\title{
Heat Characteristics Analysis of Synchronous Reluctance Motor Using FEM Coupled Electromagnetic Field and Thermal Field
}

\author{
Jung Ho Lee* and Ah Ram Jeon \\ Department of Electrical Engineering, Hanbat National University, Daejeon 305-719, Korea
}

(Received 17 February 2010, Received in final form 17 May 2010, Accepted 19 May 2010)

\begin{abstract}
This paper reports the development of an analysis method in a synchronous reluctance motor (SynRM) using the finite element method (FEM) coupled with the electromagnetic field of the Preisach model, which represents an additional thermal source due to hysteresis loss and a thermal field. This study focused on thermal analysis relative to hysteresis and copper losses in a SynRM.
\end{abstract}

Keywords : copper loss, finite element method (FEM), hysteresis loss, preisach model, synchronous reluctance motor (SynRM), thermal analysis

\section{Introduction}

Efficiency and torque/ampere are important for evaluating the performance of electrical machines.

The characteristics of electrical machines depend mainly on the behavior of various losses in the machine. Therefore, a study of the heating problems of electrical machines including the temperature rising prediction of the magnetic core, teeth, insulation, conductor etc. are essential for sophisticated design, and are extremely complex.

An accurate solution is important for maintaining the design integrity, ensuring high performance and optimizing the cost.

For this purpose, it is essential to predict more accurately the temperature distribution and its gradient in electric machines. The heat losses of SynRM results mainly from the Joule effect on the copper winding and the hysteresis loss of magnetic materials.

The heat generated by copper windings can be obtained from the results of a general process used in the heat transfer analysis method [1-5].

However, the hysteresis component in the internal thermal source has been obtained traditionally using analytical techniques, with many simplifying assumptions with respect to geometry and manufacturer material data.

The Preisach model is considered a powerful hysteresis model, and has been a major research focus $[6,7]$.

With the advent of the Preisach model, numerical techniques for modeling the additional thermal source in a

*Corresponding author: Tel: $+82-42-821-1098$

Fax: +82-42-821-1088, e-mail: limotor@hanbat.ac.kr magnetic material can be obtained.

This study performed finite element analysis coupling the electromagnetic field of the Preisach model with the thermal field of a SynRM. In addition, dynamic characteristic analyses were performed to determine the effect of Joule and hysteresis losses.

In this study, a thermal analysis method in a SynRM was developed to examine Joule and hysteresis losses.

\section{Finite Element Method Coupled Electromagnetic Field of Preisach Model \& Thermal Field}

\subsection{Governing equation of SynRM in electromagnetic} field

Maxwell's equations can be written as

$$
\begin{aligned}
& \nabla \times \vec{H}=\vec{J}_{0} \\
& (\nabla \cdot \vec{B})=0 \\
& \vec{B}=\frac{1}{v_{0}} \vec{H}+\vec{M}
\end{aligned}
$$

where $\vec{M}$ is the magnetization of magnetic material with respect to the magnetic intensity $\vec{H}$. The magnetic vector potential $\vec{A}$ and the equivalent magnetizing current is expressed as follows:

$$
\begin{aligned}
& \vec{B}=\nabla \times \vec{A} \\
& \vec{J}_{m}=v_{0}(\nabla \times \vec{M})
\end{aligned}
$$

The governing equation derived from (1) (5), is given as

$$
v_{0}(\nabla \times \nabla \times \vec{A})=\vec{J}_{0}+\vec{J}_{m}
$$




\subsection{System Matrix}

The system matrix can be written as follows:

$$
\left[\mathrm{K}^{(\mathrm{e})}\right]\left\{\mathrm{A}^{(\mathrm{e})}\right\}+\left\{\mathrm{F}^{(\mathrm{e})}\right\}+\left\{\mathrm{M}^{(\mathrm{e})}\right\}=0
$$

Where, $K_{i j}^{(e)}=\frac{v_{0}^{(e)}}{4 \Delta^{(e)}}\left(c_{i e} c_{j e}+d_{i e} d_{j e}\right), F_{i}^{(e)}=-\Delta^{(e)} \frac{N i}{3 S}$

$$
M_{i}^{(e)}=v_{0}^{(e)}\left(M_{x}^{(e)} d_{i e}+M_{y}^{(e)} c_{i e}\right)
$$

The overall model is described by the following matrix:

$$
[\mathrm{K}]\{\mathrm{A}\}+\{\mathrm{F}\}+\{\mathrm{M}\}=0
$$

\subsection{Finite element formulation of SynRM in thermal} field

In the thermal field, the finite element model corresponding to a variational formulation of the heat conduction problem with convective boundary conditions and thermal sources for a typical element is given by the following matrix equation.

$$
\begin{aligned}
{\left[\mathrm{M}^{\mathrm{e}}\right] } & \frac{\mathrm{d}}{\mathrm{dt}}\left[\mathrm{T}^{\mathrm{e}}\right]+\left(\left[\mathrm{S}^{\mathrm{e}}\right]+\left[\mathrm{H}^{\mathrm{e}}\right]+\left[\mathrm{G}^{\mathrm{e}}\right]+\left[\mathrm{G}_{\mathrm{m}}^{\mathrm{e}}\right]\right)\left[\mathrm{T}^{\mathrm{e}}\right] \\
= & {\left[\mathrm{F}^{\mathrm{e}}\right]+\left[\mathrm{F}_{\mathrm{m}}^{\mathrm{e}}\right]+\left[\mathrm{P}^{\mathrm{e}}\right]+\left[\mathrm{R}^{\mathrm{e}}\right] }
\end{aligned}
$$

where $\frac{\mathrm{d}}{\mathrm{dt}}\left[\mathrm{T}^{\mathrm{e}}\right]$ is time derivative temperature vector, $\left[\mathrm{M}^{\mathrm{e}}\right]$ is the thermal capacity matrix, $\left[\mathrm{S}^{\mathrm{e}}\right]$ is the thermal conductivity matrix, $\left[\mathrm{H}^{\mathrm{e}}\right]$ is the convection matrix, $\left[\mathrm{G}^{\mathrm{e}}\right]$ is the resistivity temperature dependency matrix, $\left[\mathrm{T}^{\mathrm{e}}\right]$ is the temperature vector, $\left[\mathrm{F}^{\mathrm{e}}\right]$ is the Heating sources vector due to the copper winding, $\left[\mathrm{F}_{\mathrm{m}}^{\mathrm{e}}\right]$ is the Heating sources vector due to hysteresis of materials, $\left[\mathrm{P}^{\mathrm{e}}\right]$ is the convective vector, $\left[\mathrm{R}^{\mathrm{e}}\right]$ and is the Boundary vector

$$
\begin{aligned}
& {\left[\mathrm{M}^{\mathrm{e}}\right]=\rho c \Delta \frac{1}{2}\left|\begin{array}{lll}
2 & 1 & 1 \\
1 & 2 & 1 \\
1 & 1 & 2
\end{array}\right|,\left[\mathrm{S}_{\mathrm{ij}}^{\mathrm{e}}\right]=\frac{\mathrm{k}}{4 \Delta}\left(\mathrm{c}_{\mathrm{i}} \mathrm{c}_{\mathrm{j}}+\mathrm{d}_{\mathrm{i}} \mathrm{d}_{\mathrm{j}}\right)} \\
& {\left[\mathrm{H}^{\mathrm{e}}\right]=\frac{\mathrm{h}_{\mathrm{ij}} \mathrm{l}_{\mathrm{ij}}}{6}\left|\begin{array}{lll}
2 & 1 & 0 \\
1 & 2 & 0 \\
0 & 0 & 0
\end{array}\right|+\frac{\mathrm{h}_{\mathrm{jk}} \mathrm{l}_{\mathrm{jk}}}{6}\left|\begin{array}{lll}
0 & 0 & 0 \\
0 & 2 & 1 \\
0 & 1 & 2
\end{array}\right|+\frac{\mathrm{h}_{\mathrm{ki}} \mathrm{l}_{\mathrm{ki}}}{6}\left|\begin{array}{lll}
2 & 0 & 1 \\
0 & 0 & 0 \\
1 & 0 & 2
\end{array}\right|} \\
& {\left[\mathrm{G}^{\mathrm{e}}\right]=-\rho_{0} \alpha \mathrm{J}^{2} \Delta \frac{1}{12}\left|\begin{array}{lll}
2 & 1 & 1 \\
1 & 2 & 1 \\
1 & 1 & 2
\end{array}\right|, \quad\left[\mathrm{F}^{\mathrm{e}}\right]=\frac{\rho_{0} \mathrm{~J}_{0}^{2}\left(1-\alpha \mathrm{T}_{0}\right) \Delta}{3}\left[\begin{array}{l}
1 \\
1 \\
1
\end{array}\right] \text {, }} \\
& {\left[\mathrm{P}^{\mathrm{e}}\right]=\frac{\mathrm{h}_{\mathrm{ij}} 1_{\mathrm{ij}} \mathrm{T}_{\mathrm{f}}}{2}\left|\begin{array}{l}
1 \\
1 \\
0
\end{array}\right|+\frac{\mathrm{h}_{\mathrm{jk}} 1_{\mathrm{jk}} \mathrm{T}_{\mathrm{f}}}{2}\left|\begin{array}{l}
0 \\
1 \\
1
\end{array}\right|+\frac{\mathrm{h}_{\mathrm{kj}} \mathrm{l}_{\mathrm{ki}} \mathrm{T}_{\mathrm{f}}}{2}\left|\begin{array}{l}
1 \\
0 \\
1
\end{array}\right|} \\
& {\left[\mathrm{R}^{\mathrm{e}}\right]=\frac{1_{\mathrm{ij}} \mathrm{T}_{0}}{2}\left|\begin{array}{l}
1 \\
1 \\
0
\end{array}\right|+\frac{1_{\mathrm{jk}} \mathrm{T}_{0}}{2}\left|\begin{array}{l}
0 \\
1 \\
1
\end{array}\right|+\frac{1_{\mathrm{ki}} \mathrm{T}_{0}}{2}\left|\begin{array}{l}
1 \\
0 \\
1
\end{array}\right|}
\end{aligned}
$$

where, $\rho_{0}$ is the electric resistivity at $\mathrm{T}_{0}$ temperature $[\Omega \cdot \mathrm{m}], \alpha$ is the linear expansion coefficient $[/ \mathrm{K}], \mathrm{T}_{\mathrm{f}}$ is the undisturbed fluid temperature $[\mathrm{K}]$, and 1 is the length between node [m]

The convective heat transfer coefficient was calculated from the following equation [4]:

$$
\mathrm{h}=\mathrm{h}_{\mathrm{f}}=\mathrm{h}_{\mathrm{n}}\left(1+1.3 \sqrt{\mathrm{v}_{\mathrm{f}}}\right)
$$

where $h_{f}$ is the forced convective heat transfer coefficient $\left[\mathrm{w} /\left(\mathrm{m}^{2} \cdot \mathrm{K}\right)\right], \mathrm{h}_{\mathrm{n}}$ is the natural convective heat transfer coefficient $\left[\mathrm{w} /\left(\mathrm{m}^{2} \cdot \mathrm{K}\right)\right]$ and $\mathrm{v}_{\mathrm{f}}$ is the average fluid velocity $[\mathrm{m} / \mathrm{s}]$.

\subsection{Additional Heating Source}

An additional heating source known as hysteresis loss can be included in the system matrix of thermal analysis according to the following new concept.

The energy dissipated per unit volume of a material and per complete cycle is the area enclosed by the B-H loop for particular limiting values of the maximum $\mathrm{H}$ or $\mathrm{B}$ in each element of the analysis model, as can be seen from the typical loop in Fig. 1. The unit is as follows:

tesla $\times$ ampere $/$ meter $=$ weber $/$ meter $^{2} \times$ ampere $/$ meter

Volt $\times$ second $\times$ ampere $/$ meter $^{3}=$ Joule $/$ meter $^{3}$

The hysteresis loss of each element $\left[\mathrm{L}^{\mathrm{e}}\right]$ relationship can be matched to $\mathrm{R}_{\mathrm{c}} \mathrm{J}_{\text {iron }}^{2}$ approximately and $\mathrm{R}_{\mathrm{c}}=\rho_{0} 1 / \mathrm{S}$.

where $R_{c}$ is the core loss resistance, and the eddy current portion for $\mathrm{R}_{\mathrm{c}}$ is infinitesimal compared to hysteresis one due to the low speed performance $(500 \mathrm{rpm})$. $\mathrm{J}_{\text {iron }}$ is not an equivalent magnetizing current density $\mathrm{J}_{\mathrm{m}}$, but an equivalent iron loss current density. $\mathrm{S}$ is the area of the element and 1 is the stack length of the SynRM.

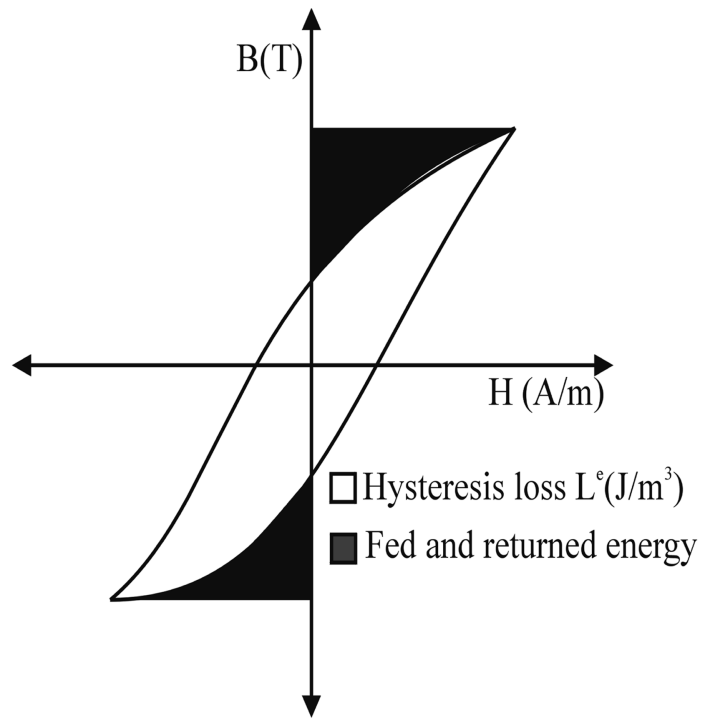

Fig. 1. Energy state of the hysteresis loop. 
Therefore, an additional heating source in 2D thermal analysis is as follows:

$$
\begin{aligned}
& {\left[\mathrm{G}_{\mathrm{m}}^{\mathrm{e}}\right]=-\left[\mathrm{L}^{\mathrm{e}}\right] \frac{\mathrm{S}}{1} \alpha \Delta \frac{1}{12}\left|\begin{array}{lll}
2 & 1 & 1 \\
1 & 2 & 1 \\
1 & 1 & 2
\end{array}\right|,} \\
& {\left[\mathrm{F}_{\mathrm{m}}^{\mathrm{e}}\right]=\frac{\left[\mathrm{L}^{\mathrm{e}}\right] \mathrm{S} / 1\left(1-\alpha \mathrm{T}_{0}\right) \Delta}{3}\left[\begin{array}{l}
1 \\
1 \\
1
\end{array}\right]}
\end{aligned}
$$

An area of the hysteresis loop, which is calculated by Preisach modeling, can be found by integration over a cycle.

$$
\mathrm{W}_{\text {1cycle }}=\text { Hysteresis_Loss } \text { 1cycle }_{1}=\int_{\text {Icycle }} \mathrm{BdH}
$$

Calculations of hysteresis loop areas are performed over the entire element of the analysis model. The next subsection deals with the Preisach model.

\subsection{Application of the Preisach Model}

Preisach modeling is a powerful method for examining the hysteresis characteristicd within a SynRM or other electric machines [8,9]. In Preisach modeling in the present study, the $\mathrm{M}-\mathrm{H}$ relation was used instead of the $\mathrm{B}-\mathrm{H}$ relation.

The analysis was performed considering the vector quantities due to the difference between the applied field and magnetization of the entire hysteresis phenomena. Otherwise, the vector analysis is complex and calculation errors are unavoidable. Therefore, the new algorithm for an analysis of rotating machines should be established.

The rotor moves synchronously according to the input current angle $\theta$, as shown in Fig. 2. Therefore, the domain in the stator is meant to be an alternating field with reference to the $\mathrm{x}$-axis and $\mathrm{y}$-axis. $\mathrm{B}$ and $\mathrm{H}$ of the domain in rotor were not only a constant and a rotating field, but also an alternating field with reference to the $\mathrm{x}-$ and $\mathrm{y}$ axis.

The angle between the applied field and magnetization is 0 or $\pi$ on the $\mathrm{x}, \mathrm{y}$-axis. A Preisach model for a rotating machine can be represented as a scalar model, which is a special feature of vector hysteresis, as shown in (12).

$\mathrm{M}$ and $\mathrm{H}$ calculated on the same axis have the same vector direction.

Therefore, magnetization $\mathrm{M}$ can be analyzed by calculating the quantity just in a rotating machine.

$$
\begin{aligned}
M(t) & =\iint_{\alpha \geq \beta} \mu(\alpha, \beta) \gamma_{\alpha \beta}(H(t)) d \alpha d \beta \\
& =\iint_{S^{+}(t)} \mu(\alpha, \beta) d \alpha d \beta-\iint_{S^{-}(t)} \mu(\alpha, \beta) d \alpha d \beta
\end{aligned}
$$

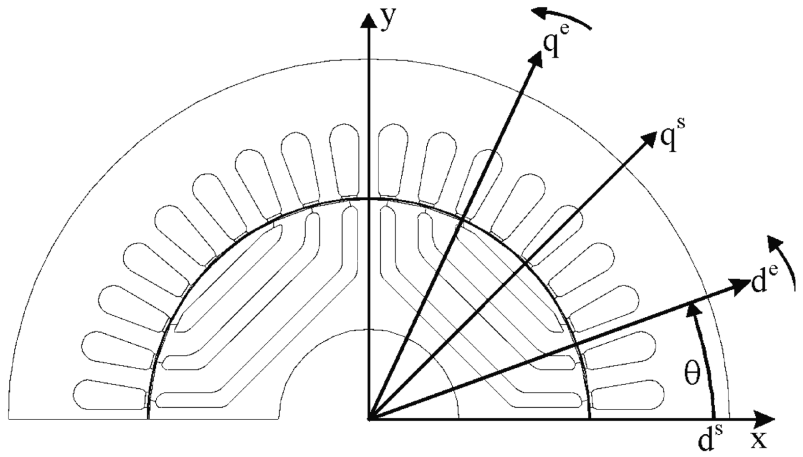

Fig. 2. Rotating(e), stationary(s), $x, y$ axis.

A more convenient treatment of this model is to substitute the Everett plane for the Preisach model, as shown in (13) [10].

$$
E(\alpha, \beta)=\iint_{\alpha \geq \beta} \mu(\alpha, \beta) \gamma_{\alpha \beta}(H(t)) d \alpha d \beta
$$

In the Everett plane, the distribution of $\mathrm{M}$ accepted from the experimental data of material S40 are Gaussian.

\section{Calculation Procedure}

Fig. 3 shows a flowchart of transient thermal analysis of a SynRM using electromagnetic of Preisach's model coupled with the thermal finite element method taking rotation into account.

The FEM of an electromagnetic field is a current source problem, which is divided by the sampling time $\Delta \mathrm{t}$, and synchronous speed of steady state analysis is $500 \mathrm{rpm}$. The sources of thermal field analysis are the current density, which is divided by the sampling time $\Delta t$, and the hysteresis loss area $L^{\mathrm{e}}$, which is calculated using the

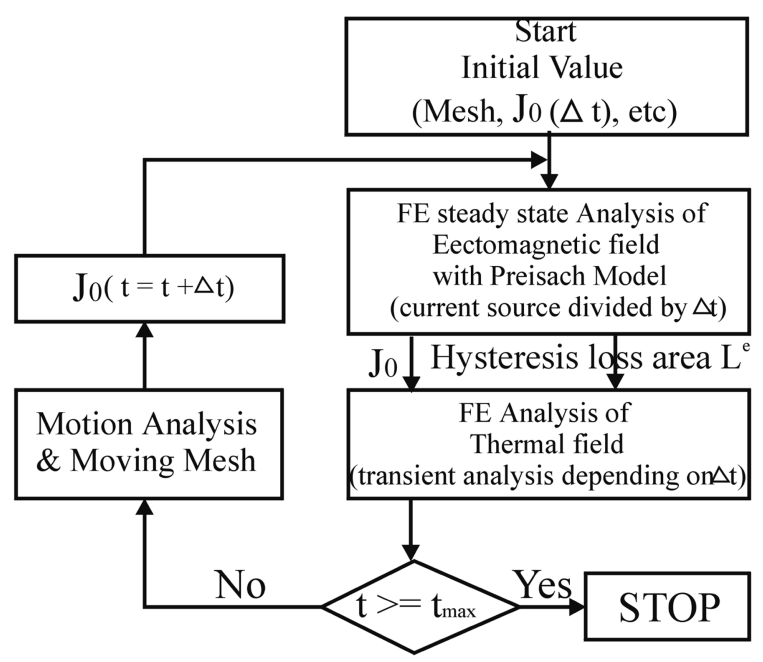

Fig. 3. Flowchart of analysis. 


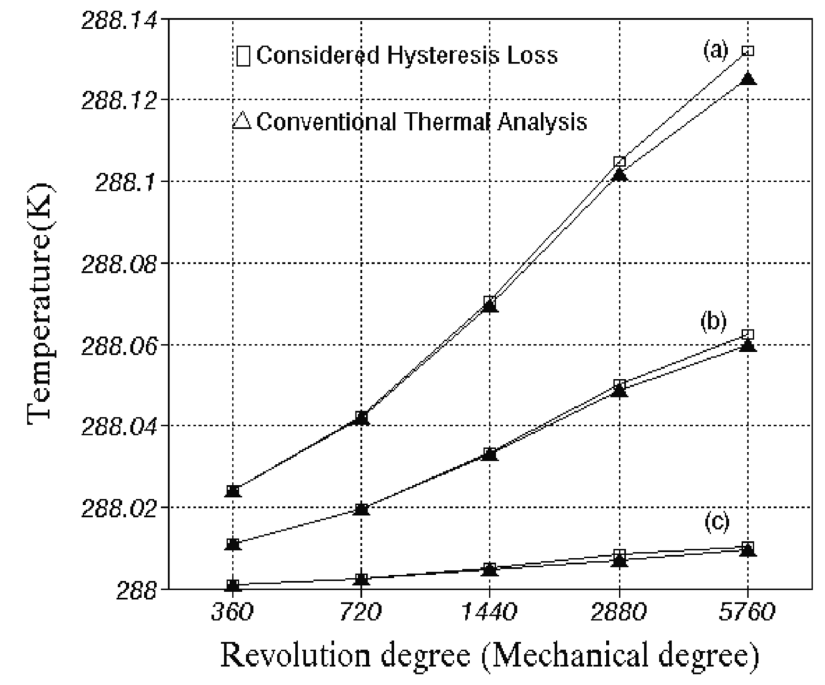

Fig. 4. Temperature rising of the elements of stator, rotor and the whole SynRM.

electromagnetic field coupled with the Preisach model. The thermal analysis is transient and dependent on time.

\section{Result And Discussion}

Fig. 4 shows the temperature rising data of the analysis model in the proposed method and conventional method. The (a) group shows the temperature rising in an element of stator teeth, and the (c) group shows the temperature rising in an element of the rotor.

The rotor would have almost zero loss because the spatial flux wave in a SynRM is rotating at the same angular velocity as the rotor. As a result, the rotor flux wave is constant.

Therefore, most hysteresis losses in the stator and rotor are infinitesimal, as shown in Fig. 4(a), (c).

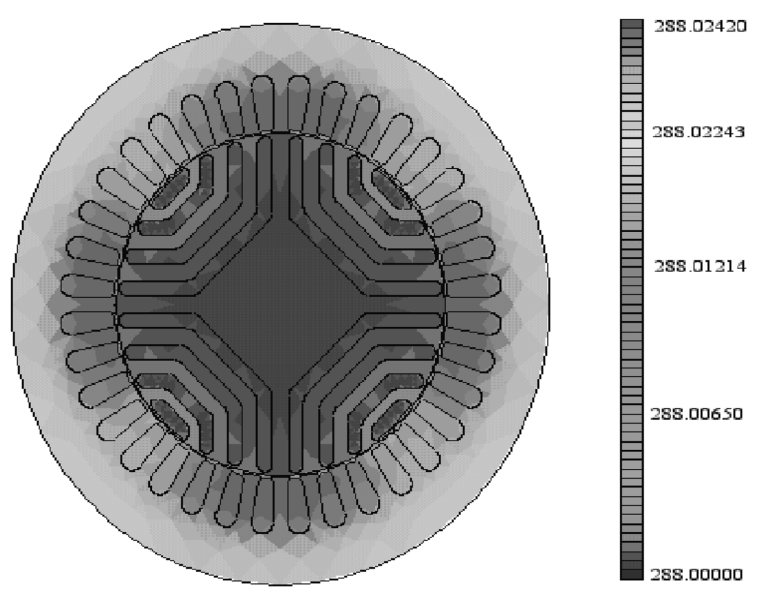

Fig. 5. Temperature distributions of SynRM in $360^{\circ}$.

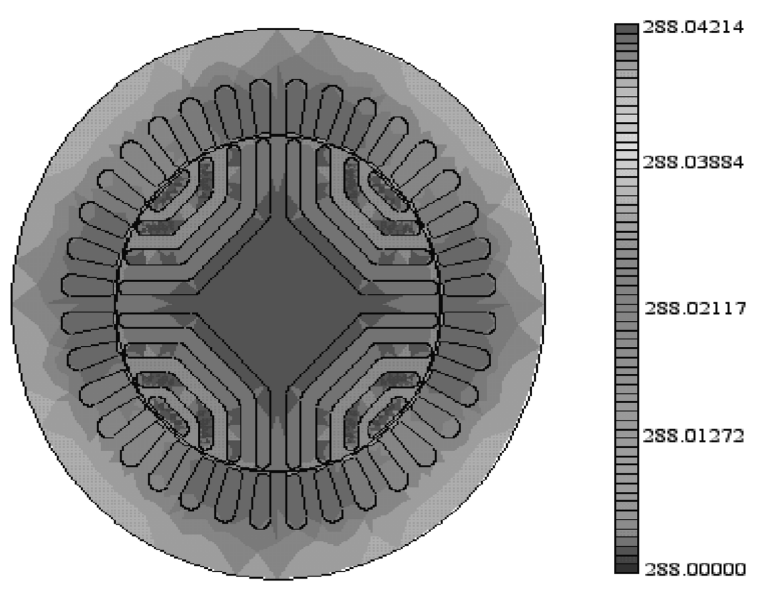

Fig. 6. Temperature distributions of SynRM in $720^{\circ}$.

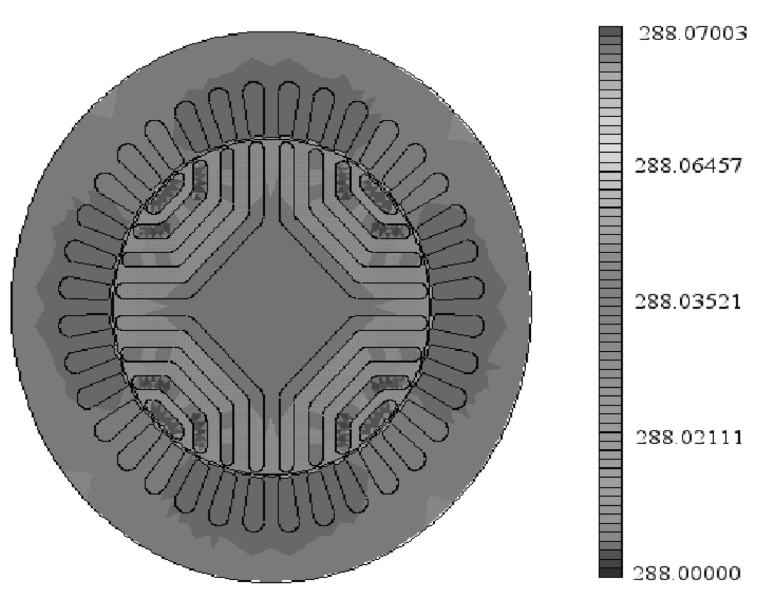

Fig. 7. Temperature distributions of SynRM in $1440^{\circ}$.

The (b) group represents the total temperature rising of an analysis model. The temperature rising rates of the proposed method compared to the conventional methods were $0.0044 \%$ at $360^{\circ}, 0.0078 \%$ at $720^{\circ}, 0.0149 \%$ at $1440^{\circ}, 0.0288 \%$ at $2880^{\circ}$ and $0.0416 \%$ at $5760^{\circ}$. It is natural that the temperature rising rates of the proposed method increase with increasing revolution angle (mechanical angle) or frequency in proportion to hysteresis loss rising.

Figs. 5, 6 and 7 show the thermal distributions series in $360^{\circ}, 720^{\circ}$ and $1440^{\circ}$, respectively. Most of the temperature distributions were in the stator, and the temperature distribution in the rotor is infinitesimal. As a result, most losses (copper, hysteresis loss) of SynRM occur in the stator.

\section{Conclusion}

Where possible, without incurring undue complexity, the heat transfer coefficients derived in this paper were 
used as general coefficients. Issues, such as the heat transfer coefficient are important and a complex problem in the physical field because the use of a general approach without adequate attention to the physical model can frequently lead to serious error. However, these problems will require more research.

The main focus of the paper was to derive a thermal transient solution for SynRM from a conventional heating source (copper loss) and another heating source related to hysteresis loss. The proposed method showed that additional thermal rising occurs in each element of the analysis model.

Such an approach to the loss problem of electrical machines will provide a valuable aid for those in search of high performance machine design methods.

More research of the theme, both physically and numerically, is currently underway.

\section{References}

[1] K. H. Huebner, E. A. Thornton, and T. G. Byron, The Finite Method For Engineers, John Wiley \& Sons, New York (1995).

[2] M. Jarnieux, G. Reyne, and G. Meunier, IEEE Trans. Magn. 29, 3312 (1994).

[3] C. C. Chan, Lietong Yan, Pizhang Chen, Zezhong Wang, and K. T. Chau, IEEE Trans. Magn. 9, 53 (1994).

[4] J. A. D. Pinto, A. P. B. Coimbra, and C. F. R. L. Antunes, IEEE Trans. Magn. 30, 3339 (1994).

[5] Daniela Carstea, Ion Carstea, and Alexandru Carstea, IEEE Trans. Magn. 2, 475 (2005).

[6] A. Ivanyi, Hysteresis Models in Electromagnetic Computation, Akademiai Kiado, Budapest (1997).

[7] I. D. Mayeroyz, IEEE Trans. Magn. 22, 603 (1986).

[8] J. H. Lee, J. C. Kim, and D. S. Hyun, IEEE Trans. Magn. 34, 2629 (1998).

[9] J. H. Lee, J. C. Kim, and D. S. Hyun, Physica B 275, 238 (2000).

[10] D. H. Everett, Trans. Faraday Soc. 50, 1077 (1954). 